\title{
Rotational stability and visual outcomes with the implantation of the enVista MX60T TORIC intraocular lens
}

\section{Estabilidad rotacional y resultados visuales con implante de lente intraocular enVista TORIC MX60T}

Flor D. Guzmán-Iturbe*, Eduardo Chávez-Mondragón, Diego Zamora-de la Cruz, Amanda Cáceres-Marín, Daniela Pulido-London and Karla Ruiz-Álvarez

Anterior Segment Department, Instituto de Oftalmología Fundación Conde de Valenciana, Mexico City, Mexico

\begin{abstract}
Objective: To review the results and rotational stability of the enVista MX60T TORIC intraocular lens. Methods: A prospective and longitudinal study was carried out; phacoemulsification surgery was performed with MX60T toric lens implantation. At week one, month one and month three, uncorrected visual acuity (UCVA) and spherical equivalent were evaluated. At each visit, the alignment of the toric lens was evaluated using the OPD-Scan III "toric summary"(Refractive Power/Corneal Analyzer, NIDEK ${ }^{\circ}$. Results: Twenty eyes $(n=20)$ were included. Mean preoperative uncorrected visual acuity (UCVA) was 0.84 logMAR, and at the final visit UCVA was $0.004 \log$ MAR $(p<0.0001)$. Mean preoperative corneal astigmatism was -2.50 diopters; at the final visit mean refractive astigmatism was -0.34 diopters $(p<0.0001)$. Ninety percent of the eyes had a final vision of $20 / 25$ or better. The average rotation of the lens was $2.05^{\circ}$ with a range of $0-5$. There was no relationship between the axial length and the amount of lens rotation $(p<0.40)$. Final UCVA was related to the degree of final astigmatism $(p=0.001)$. None of the eyes showed glistening or required posterior YAG capsulotomy. Conclusions: The enVista MX60T toric intraocular lens showed good visual results and excellent rotational stability in the mid-term (3 months). Therefore, it can be considered as an excellent therapeutic option in patients with cataract and regular corneal astigmatism.
\end{abstract}

Key words: Cataract. Toric. Astigmatism. Intraocular lens. EnVista.

\section{Resumen}

Objetivo: Evaluar los resultados visuales y la estabilidad rotacional del implante del lente intraocular enVista TORIC MX60T. Metodología: Mediante un estudio prospectivo y longitudinal se realizó cirugía de facoemulsificación con implante del lente enVista TORIC MX60T. A la semana uno, al mes uno y al mes tres se realizó evaluación de la agudeza visual sin corrección (AVSC) y equivalente esférico. Se evaluó en cada cita la alineación del lente tórico mediante Toric Summary del topógrafo OPD-Scan III (Refractive Power/Corneal Analyzer, NIDEK ${ }^{\circ}$. Resultados: Se incluyeron 20 ojos, con una edad promedio de 64.3 años, la media de la longitud axial fue de $23.50 \mathrm{~mm}$. La AVSC preoperatoria promedio fue de 0.84 logMAR $y$ en la visita final fue de $0.004 \log M A R(p<0.0001)$. El astigmatismo corneal preoperatorio promedio fue de -2.50 dioptrías, en la visita final el astigmatismo refractivo fue de -0.34 dioptrías $(p<0.0001)$. La rotación promedio del lente fue de $2.05^{\circ}$, con un rango de 0-5. No existió relación entre la longitud axial y la cantidad de rotación del lente $(p<0.40)$. La AVSC final

Correspondence:

*Flor Daniela Guzmán-Iturbe

Laguna de las flores 1084

Col. La Salle Saltillo, Del. Coahuila

Date of reception: 28-02-2017

Date of acceptance: 10-07-2017

DOI: 10.24875/RMOE.M18000012
Available online: 14-05-2018 Rev Mex Oftalmol (Eng).2018;92(3):108-114 www.rmo.com.mx license (http://creativecommons.org/licenses/by-nc-nd/4.0/). 
se relacionó con el grado de astigmatismo final ( $p=0.001)$. Ningún paciente requirió capsulotomía posterior y no se observó mediante evaluación clínica desarrollo de glistening. Conclusiones: El lente intraocular enVista TORIC MX60T mostró buenos resultados visuales y excelente estabilidad rotacional a mediano plazo de seguimiento (3 meses), por lo que se puede considerar como una excelente opción terapéutica en pacientes con catarata y astigmatismo corneal regular.

Palabras clave: Catarata. Tórico. Astigmatismo. Lente intraocular. EnVista.

\section{Introduction}

Cataract is the leading cause of reversible blindness in the world ${ }^{1}$. Advances in cataract surgery have now led to the search for emmetropia ${ }^{2}$. The prevalence of corneal astigmatism in subjects with cataract is variable and, although it is generally reported as 1 diopter, it becomes significant in $20 \%$ to $22 \%$ of the population ${ }^{3-5}$. When both cataract and astigmatism coexist, the option of correcting both during the same surgical procedure should always be considered. There are several options historically performed for the correction of astigmatism in cataract surgery ${ }^{6-10}$. However, since the advent of toric lenses there is an increasing preference for this option, since they not bear the complications inherent to corneal incisions; however, its main drawback remains stability. For each degree of lens rotation inside the capsular bag, $3.3 \%$ of the cylinder power correction is lost, and thus, a third of the power is lost when it comes to a rotation of 10 degrees $^{11}$. The Toric MX60T enVista lens is an aspheric, hydrophobic acrylic (partially hydrated) lens, with fenestrated haptics, containing its cylinder power on the back surface, with powers for astigmatic correction at the corneal plane ranging from 1.25, 2.00, 2.75, 3.50, 4.25, 5.00 and 5.75 diopters (Fig. 1).

\section{Objective}

The purpose of this study is to evaluate visual results and rotational stability after cataract surgery with the enVista TORIC MX60T lens implantation (Bausch and Lomb $^{\circledR}$ )

\section{Methods}

\section{Preoperative evaluation}

A prospective, interventional and longitudinal study was carried out in patients of the Instituto de Oftalmología Fundación Conde de Valenciana. The study fulfilled the Helsinski criteria and was approved by the research and ethics in research committees of the institution. All subjects with senile cataract and low vision attributable to lens opacity who also had regular

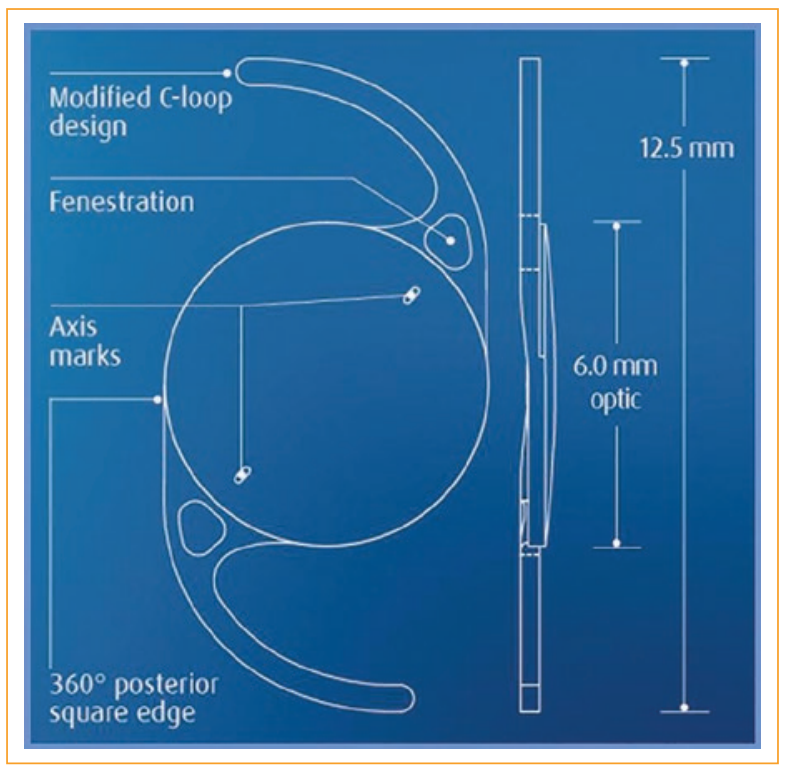

Figure 1. MX60T lens design.

corneal astigmatism between 1.00 and 4.50 diopters (OPD-Scan III Refractive Power/Corneal Analyzer, NIDEK ${ }^{\circledR}$ ) were included (Fig. 2). A complete ophthalmological examination was performed, excluding patients with any ocular or systemic pathology that could affect the postoperative visual outcome, such as high myopia, glaucoma, diabetic retinopathy or age-related macular degeneration, patients with ocular pathology that affected lens stability inside the capsular bag, such as traumatic zonular dialysis or zonular weakness secondary to pseudoexfoliation syndrome. All these patients were informed about the research protocol; those who agreed to participate signed an informed consent form.

The calculation of the lens spherical power used the SRK/T formula, with data obtained from the following tests:

- Ocular biometry by interferometry (AL-Scan Optical Biometer, NIDEK ${ }^{\circledR}$ )

- Keratometry average based on corneal topography (OPD-Scan III Refractive Power/Corneal Analyzer, $\left.\mathrm{NIDEK}^{\circledR}\right)$

The estimation of the alignment of the toric lens was made with the Bausch and Lomb ${ }^{\circledR}$ calculator, available 


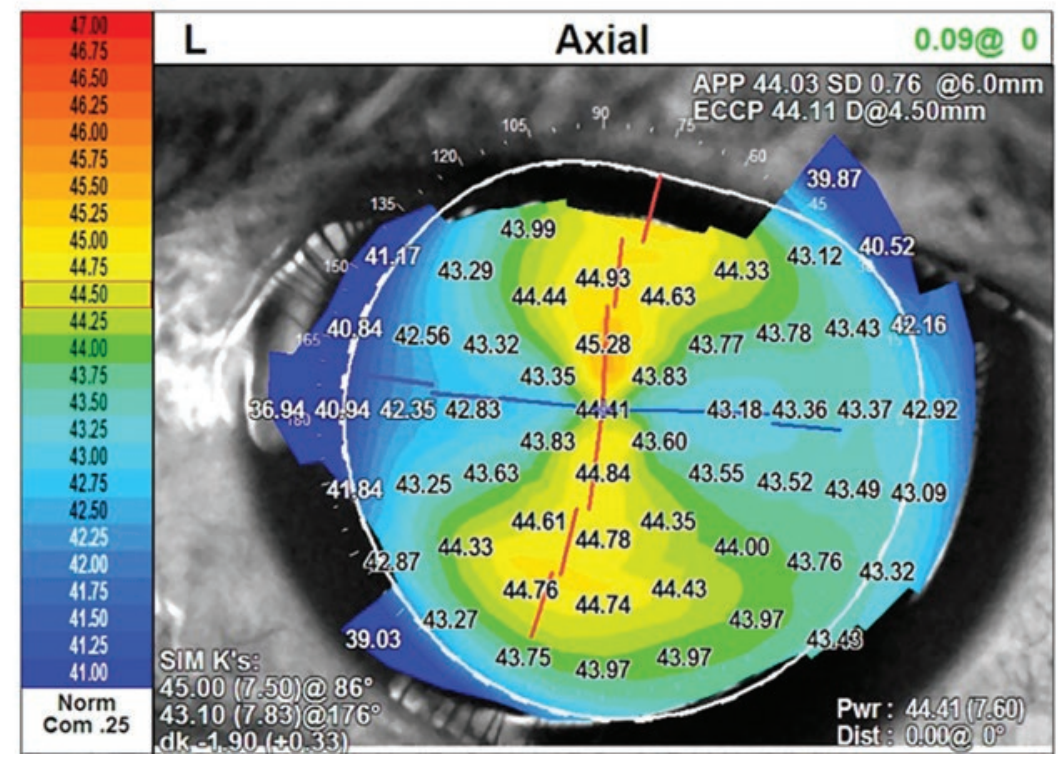

Figure 2. Topography, axial map showing symmetric and orthogonal corneal astigmatism.

on the website, by capturing the keratometry values obtained by corneal topography. https://envista.toriccalculator.com (Fig. 3).

\section{Surgical technique}

On the day of surgery, corneal marking by slit lamp was performed with corneal de-epithelialization minutes before surgery at 0 and $180^{\circ}$. Antisepsis was performed with $10 \%$ povidone iodine on the surface of the skin and $5 \%$ povidone iodine on the conjunctiva; after placing the sterile dressing and before the corneal incision, the marking indicated by the computer was performed, taking as a reference the previously mentioned marks. Subsequently, phacoemulsification was performed with a $2.8 \mathrm{~mm}$ clear cornea incision; trypan blue was used only if necessary, determined subjectively by the surgeon; continuous circular capsulorhexis with a 4.5-5 $\mathrm{mm}$ diameter was performed; the nucleus was removed with stop and chop phacoemulsification technique, and cortex remains were aspirated by coaxial mode. During surgery, Amvisc Plus ${ }^{\circledR}$ viscoelastic (1.6\% sodium hyaluronate, Bausch and Lomb $\left.{ }^{\circledR}\right)$ was used, with subsequent implantation of the MX60T lens, with a 5-10 degree alignment anterior to the pre-established degree, emphasizing viscoelastic aspiration between the lens and the capsular bag to avoid rotation in the postoperative period. It should be noted that, inside the bag, the lens can rotate clockwise and counterclockwise until it reaches its final position. The same subspecialist in Microsurgery of the Anterior Segment performed the procedures. In the immediate postoperative period, topical treatment with $1 \%$ prednisolone and moxifloxacin was administrated. The steroid was reduced gradually depending on the degree of postoperative inflammation.

\section{Postoperative evaluation}

The review was the standard one, at 24 hours and one week, with additional visits if necessary according to the individual clinical evolution. The following variables were evaluated at 1 week, 1 month and 3 months: uncorrected visual acuity (with the Snellen chart converted to $\log M A R$ ), best corrected visual acuity (with the Snellen chart converted to logMAR), residual refractive error expressed in spherical equivalent (SE) and toric lens alignment in degrees under maximum pharmacological mydriasis (Fig. 4) using the OPDScan III Refractive Power/Corneal Analyzer, NIDEK ${ }^{\circledR}$, with the function available in the program software called Toric Summary to manually measure the degree of alignment (Fig. 5). At each visit, a slit lamp evaluation of the presence or absence of posterior capsule opacity was also made, as well as an evaluation of the presence of glistening. 


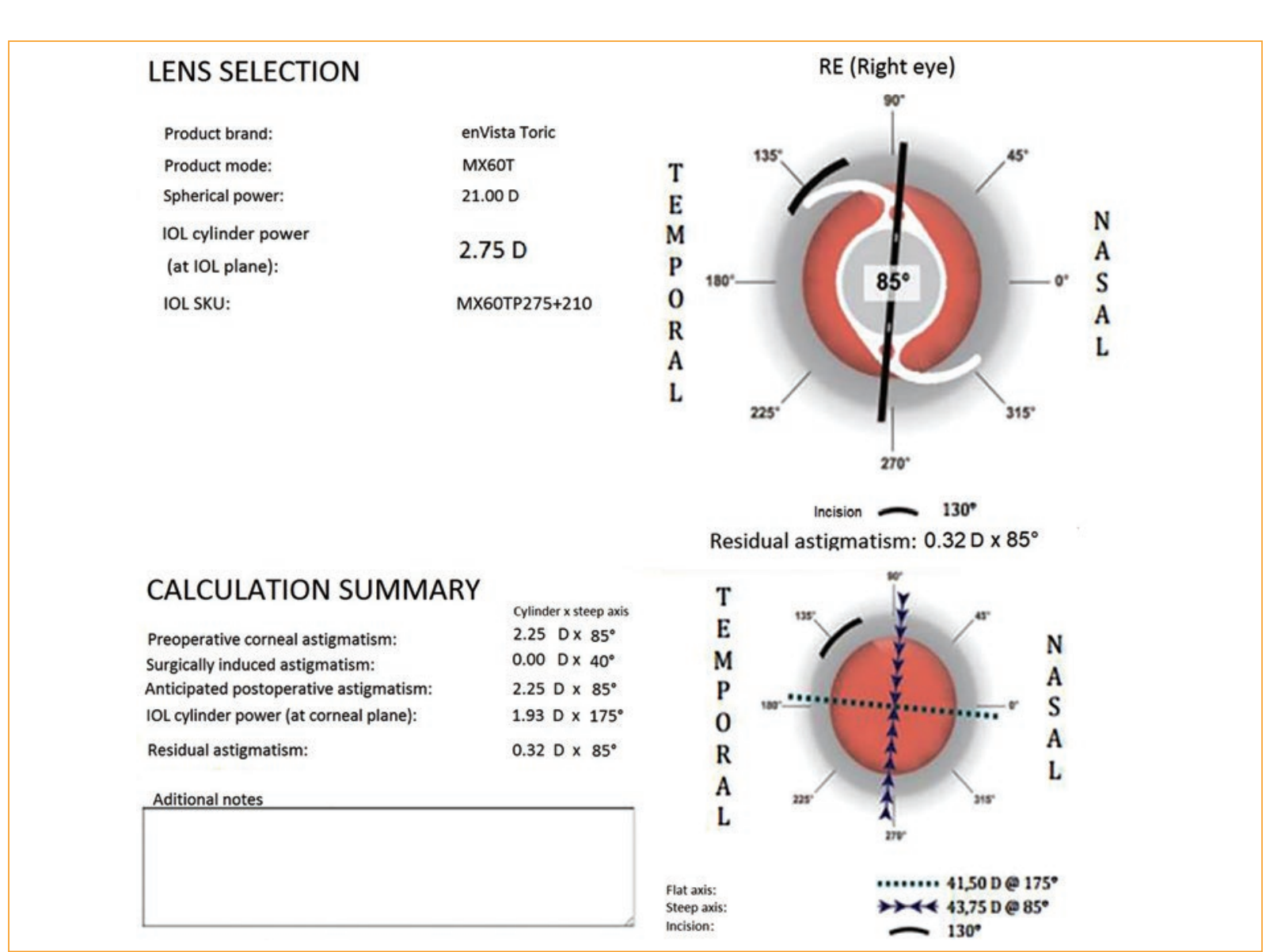

Figure 3. Example of data yielded by the online calculator.

\section{Statistical analysis}

Results were analyzed using the Wilcoxon test for median comparison, with a $95 \%$ confidence interval. Pearson correlation tests were performed for association between variables. Data was collected and analyzed using the Microsoft Office Excel 2010 program and the IBM SPSS Statistics version 20 program. A statistically significant $p$ value was considered when it was less than 0.05 .

\section{Results}

Twenty eyes of 16 patients $(n=20)$ were included in the study; none of the patients was excluded. The average age was $64.3 \pm 9.9$ years and $95 \%$ were women. Regarding the preoperative ocular characteristics, laterality was $60 \%$ left eye and $40 \%$ right eye; average axial length was $23.50 \pm 0.90 \mathrm{~mm}$, average corneal astigmatism was $2.50 \pm 0.98$ diopters, with a keratometry average of $43.83 \pm 1.34$. The average spherical power of the implanted intraocular lens was 21.25 diopters.
Average preoperative uncorrected visual acuity (UCVA) was $0.84 \pm 0.48 \log M A R$ with a median of 0.76 , and best-corrected visual acuity (BCVA) was $0.585 \pm 0.41$ logMAR with a median of 0.53 . Table 1 shows a summary of preoperative characteristics.

There were no trans- or postoperative complications and all subjects completed the follow-up. Finalaverage postoperative UCVA was $0.004 \pm 0.19$ logMAR. When comparing the initial and final UCVA, statistical significance was obtained $(p<0.0001)$. Average postoperative SE was $-0.30 \pm 0.23$; regarding final refractive astigmatism, an average of $0.34 \pm 0.51$ diopters was found and the comparison between the preoperative corneal and postoperative final refractive astigmatism showed a statistically significant difference $(p<0.0001)$; average postoperative corneal astigmatism was 2.37 \pm 1.01 and when comparing the pre- and postoperative average, no statistical significance was found ( $p>$ 0.48). Ninety percent of the eyes had a final UCVA equal to or better than $20 / 25$. The average rotation with respect to the planned axis was $2.05^{\circ}$ with a 


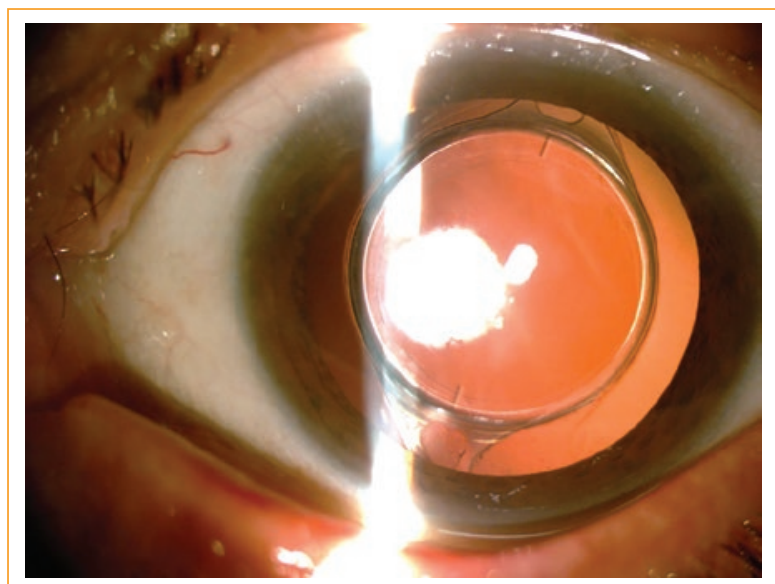

Figure 4. Image of the lens evaluated under pharmacological mydriasis.

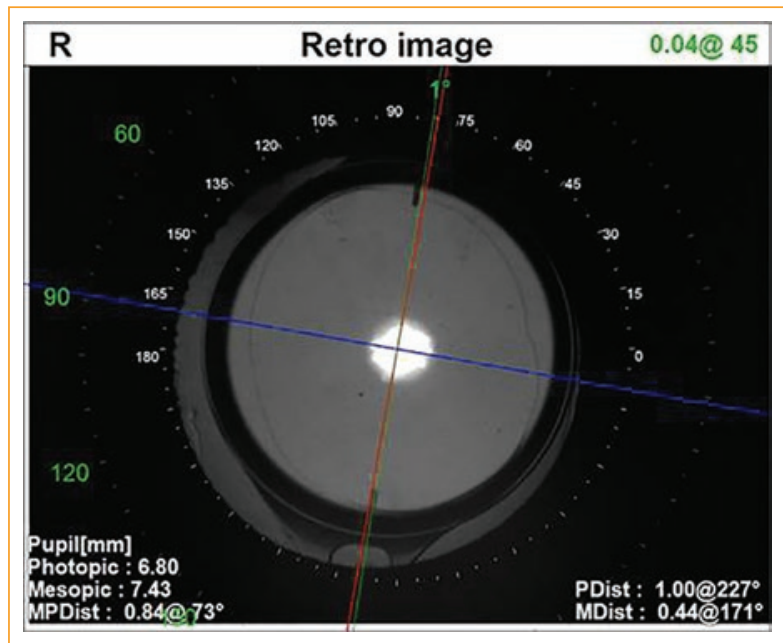

Figure 5. Example of the image obtained from the OPD-Scan III, showing a red line corresponding to the most steeped corneal axis (alignment axis of the toric lens), a blue line corresponding to the corneal plane and a green line that can be manually manipulated to align it with the marks of the implanted toric lens. In this case it is observed that there is a loss of alignment of $1^{\circ}$ (space between the red and the green line).

range from 0 to $5 ; 85 \%$ of the lenses had a rotation less than $3^{\circ}$ (Tables 2 and 3 and Fig. 6 ). When performing the correlation between the amount of rotation of the lens and the axial length, no statistical significance was found ( $p>0.40$ ).

We found a negative linear relationship with statistical significance $(p=0.001)$ when we compared the final UCVA and the final refractive astigmatism (Pearson's $p=0.690$ ) (Fig. 7).
Table 1. Preoperative characteristics

\begin{tabular}{l|r|}
\hline Preoperative characteristics & $23.50 \pm 0.90 \mathrm{~mm}$ \\
\hline Average axial length & $43.83 \pm 1.34$ \\
\hline Keratometry average & $-2.50 \pm 0.98$ diopters \\
\hline Average corneal astigmatism & $0.841 \pm 0.48$ \\
\hline Average UCVA (LogMAR) & $0.585 \pm 0.41$ \\
Average BCVA (LogMAR) & \\
\hline BCVA: best-corrected visual acuity; UCVA: uncorrected visual acuity. \\
\hline
\end{tabular}

\begin{tabular}{l|r|}
\hline Postoperative characteristics & \\
\hline Average UCVA (LogMAR) & $0.004 \pm 0.19$ \\
\hline Average refractive astigmatism & $-0.34 \pm 0.51$ \\
Average spherical equivalent & $-0.30 \pm 0.23$ \\
Average rotation & $2.05^{\circ}$ \\
UCVA: uncorrected visual acuity. & \\
& \\
Discussion & \\
\end{tabular}

Correction of corneal astigmatism in cataract surgery has the best results when a toric lens is implanted, where rotational stability is the most important characteristic, since as previously mentioned, there is a $3.3 \%$ loss of the total astigmatism correction for each degree of lens rotation. With the excellent results reported with toric lenses, their use has become an indication and not an option in patients who are good candidates.

The results obtained in the present study are similar, even better, compared to results in other studies in terms of rotational stability and visual results of toric lenses. When discussing different lens designs we found that Zarranz, et al. performed an evaluation of the Acrysof ${ }^{\circledR}$ toric intraocular lens, which has a platform similar to the MX60T with $C$ haptics, analyzing a total of 54 eyes and a 2-month follow-up. The average preoperative astigmatism was -2.25 diopters and in the final follow-up it was -0.32 diopters $(p<0.001)$; mean rotation during follow-up was $3.87^{\circ}$; therefore, it was higher compared to our results ${ }^{12}$. Bascaran, et al. studied the visual results, as well as the rotational stability of the TORBI ${ }^{\circledR} 709 \mathrm{M}$ toric lens, which, unlike the lens used in our protocol, has a plate platform. Forty-eight eyes were included and they found an UCVA of 20/40 or better in $88.1 \%$ of the cases with a 6 -month 
Table 3. Comparison of paired variables (UCVA and astigmatism)

\begin{tabular}{|c|c|c|c|c|}
\hline & Preoperative & Final & Pvalue & \\
\hline Average UCVA (LogMAR) & 0.841 & 0.004 & $<0.0001$ & $\frac{\infty}{0}$ \\
\hline Average astigmatism & -2.5 (corneal) & $\begin{array}{c}-0.34 \text { (refractive) } \\
-2.37 \text { (corneal) }\end{array}$ & $\begin{array}{c}<0.0001 \\
>0.48\end{array}$ & $\frac{2}{2}$ \\
\hline
\end{tabular}

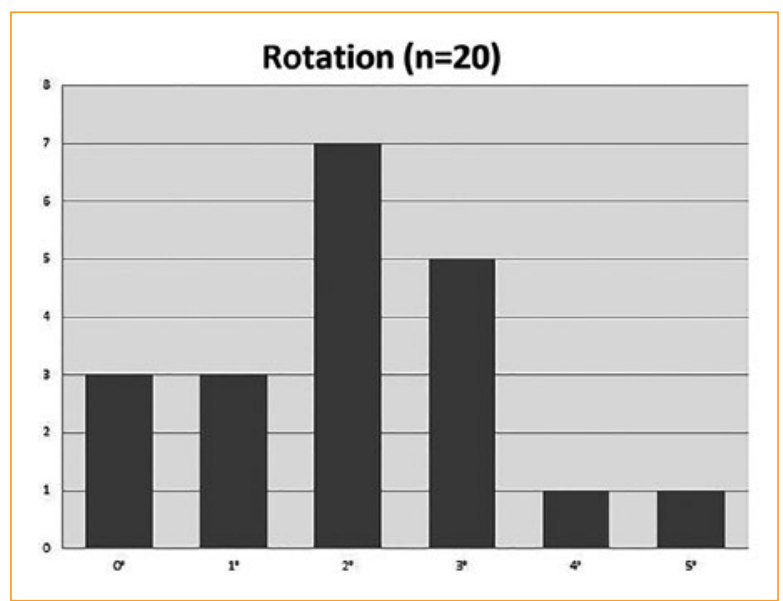

Figure 6. Frequency for each degree of lens rotation.

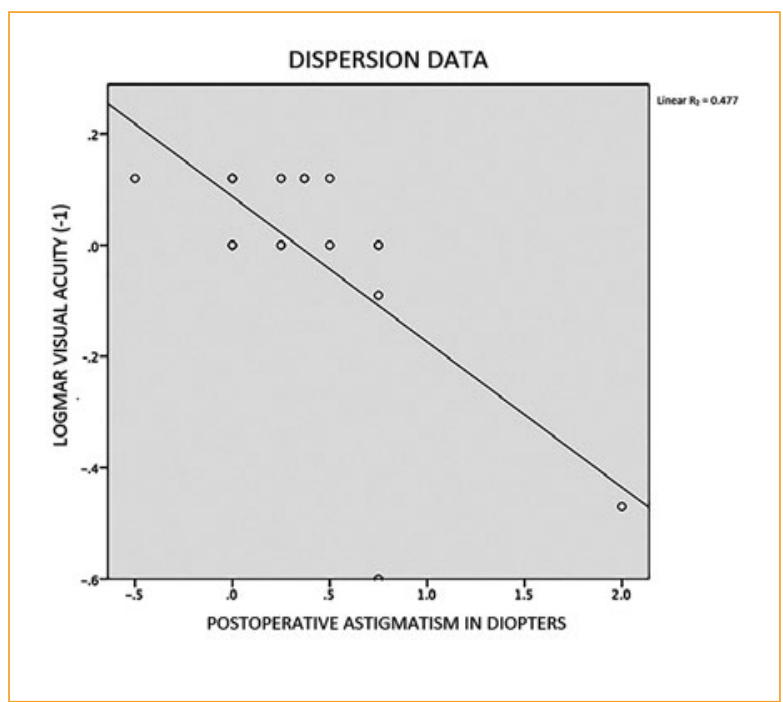

Figure 7. Table of dispersion points showing the linear relationship between the highest final UCVA and the lower final refractive astigmatism.

follow-up, and better than $20 / 25$ in $61.9 \%$ of the cases. The average cylinder decreased from -2.24 to -0.43 in the postoperative period; average rotation in this study was $4.42^{\circ}$ (from 0 to $16^{\circ}$ ), and $86 \%$ rotated less than 10 degrees $^{13}$. Lubinski, et al. evaluated 27 eyes during 6 months with the Tecnis ${ }^{\circledR}$ Toric ZCT (Abbot Medical Optics) intraocular lens implantation, which has an optical platform and C haptics, similar to Acrysof ${ }^{\circledR}$ and MX60T. In their results, they had two patients with rotation greater than $5^{\circ}$, in whom the lens was repositioned in a second surgery; final average visual acuity was 20/27 (0.14 logMAR). The cylinder decreased from -3.73 to -1.42 diopters without observing changes in the keratometric cylinder, and the average rotation was $1.1^{\circ}$, a little lower than the one observed in our study, where average visual acuity improved from 0.84 to $0.004 \log M A R$, which was statistically significant, and average astigmatism changed from -2.50 to -0.34 $\left(p<0.001\right.$ ), with an average rotation of $2.05^{\circ}$ (range from $\left.0-5^{\circ}\right)^{14}$. Sheppard performed an evaluation of the same lens, with a 2-month follow-up, and found a final UCVA of 0.15 (logMAR), with an average rotation of $3.4^{\circ 15}$. Ferreira, et al. made a comparison of the visual results of two toric lenses: AMO Tecnis ${ }^{\circledR}$ and Alcon Acrysof $^{\circledR}$, with 40 eyes included in both groups, without finding statistically significant differences when comparing UCVA, BCVA, SE and residual refractive astigmatism. The first group had an average rotation of $3.25^{\circ}$ and the second one of $3.15^{\circ}$. None of the patients presented a rotation greater than $10^{\circ 16}$.

Of course, it is difficult to perform a reliable comparison of visual results and rotational stability with other studies, since the differences in methodology, such as the characteristics of the patients, the type of topography used to obtain the keratometries, the method used for optical biometry (applanation, immersion or interferometry) and for corneal marking and the surgical technique, as well as the method used to evaluate the lens axis in the postoperative period, influence the results. We must always take into account known factors that have a negative impact on the rotational stability of any toric lens, such as an axial length greater than $25 \mathrm{~mm}$ (with a large target-to-target distance), with-the-rule astigmatism, lens material different from 
acrylic, incomplete removal of viscoelastic, as well as the size of the capsulorhexis when it does not cover the total of the optic, 360 degrees ${ }^{17,18}$.

The main limitation of our study is the sample size and the mid-term follow-up, both possibly modifiable in the future. In our study, the amount of lens rotation for the final visual result was fundamental, since, as reported, the higher the final refractive astigmatism, the worse the final visual acuity. The case with the worst visual acuity was the one with the highest amount of lens rotation, which, in addition, did not improved due to a possible refractive amblyopia.

\section{Conclusion}

The enVista ${ }^{\circledR}$ TORIC MX60T intraocular lens showed good visual results and excellent rotational stability in the mid-term follow-up (3 months), so it can be considered as a therapeutic option in patients with cataract and regular corneal astigmatism.

\section{Ethical disclosures}

Protection of human and animal subjects. The authors declare that no experiments were performed on humans or animals for this study.

Confidentiality of data. The authors declare that they have followed the protocols of their work center on the publication of patient data.

Right to privacy and informed consent. The authors have obtained the written informed consent of the patients or subjects mentioned in the article. The corresponding author is in possession of this document.

\section{Funding}

The authors declare that the intraocular lenses used in this research protocol were donated by Bausch \& Lomb.

\section{Conflict of interest}

The authors of this study have no conflict of interest to declare.

\section{References}

1. Prokofyeva E, Wegener A, Zrenner E. Cataract prevalence and prevention in Europe: a literature review. Acta Ophthalmol. 2013;91:395-405.

2. Zarranz J, Moreno J, Caire J, González J, Fernández E, Sádaba L. Implante de lentes intraoculares tóricas Acrysof ${ }^{\circledR}$ en cirugía de la catarata. Arch Soc Esp Oftalmol. 2010;85(8):274-7.

3. Hoffer KJ. Biometry of 7500 cataractous eyes. Am J Ophtalmol. 1980;90: 360-368.

4. Ferrer-Blasco T, Montés-Micó R, Peixoto-de-Matos SC, GonzálezMéijome JM, Cerviño A. Prevalence of corneal astigmatism before cataract surgery. J Cataract Refract Surg. 2009;35:70-5

5. Khan M, Muhtaseb M. Prevalence of corneal astigmatism in patients having routine cataract surgery at a teaching hospital in the United Kingdom. J Cataract Refract Surg. 2011;37:1751-5.

6. Diakonis V, Yesilirmak N, Cabot F, Kankariya V, Kounis G, Warren D, et al. Comparison of surgically induced astigmatism between femtosecond laser and manual clear corneal incisions for cataract surgery. J Cataract Refract Surg. 2015;41:2075-80.

7. Kymionis G, Yoo S, Ide T, Culbertson W. Femtosecond-assisted astigmatic keratotomy for post-keratoplasty irregular astigmatism. J Cataract Refract Surg. 2009;35:11-3.

8. Hirnschall N, Gangwani V, Crnej A, Koshy J, Maurino V, Findl O. Correction of moderate corneal astigmatism during cataract surgery: Toric intraocular lens versus peripheral corneal relaxing incisions. J Cataract Refract Surg. 2014;40:354-61.

9. Budak K, Friedman NJ, Koch DD. Limbal relaxing incisions wirh cataract surgery. J Cataract Refract Surg. 1998;24:503-8.

10. Ayala M, Pérez-Santoja J, Artola A, Claramonte P, Alió JL. Laser in situ keratomileusis to correct residual myopia after cataract surgery.J Refract Surg. 2001;17:12-6.

11. Novis C. Astigmatism and toric intraocular lenses. Curr Opin Ophthalmol. 2000;11(1):47-50

12. Zarranz J, Moreno J, González J, Fernández E, Sádaba LM. Acrysof ${ }^{\circledR}$ toric intraocular lens implantation in cataract surgery. Arch Soc Esp Oftalmol. 2010;85(8):274-7.

13. Bascaran L, Mendicute J, Macias B, Arbelaitz N, Martinez I. Efficacy and stability of AT TORBI 709 M toric IOL. J Refract Surg. 2013;29(3):194-9.

14. Lubiński W, Kaźmierczak B, Gronkowska-Serafin J, Podboraczyaska-Jodko K. Clinical Outcomes after Uncomplicated Cataract Surgery with Implantation of the Tecnis Toric Intraocular Lens. J Ophthalmol. 2016;2016:3257217.

15. Sheppard AL, Wolffsohn JS, Bhatt U, Hoffmann PC, Scheider A, Hütz WW, et al. Clinical outcomes after implantation of a new hydrophobic acrylic toric IOL during routine cataract surgery. J Cataract Refract Surg. 2013:39:41-7.

16. Ferreira TB, Almeida A. Comparison of the visual outcomes and OPDscan results of AMO Tecnis toric and Alcon Acrysof IQ toric intraocular lenses. J Refract Surg. 2012;28(8):551-5.

17. Miyake T, Kamiya K, Amano R, lida Y, Tsunehiro S, Shimizu K Longterm clinical outcomes of toric intraocular lens implantation in cataract cases with preexisting astigmatism. J Cataract Refract Surg. 2014; 40:1654-60.

18. Krall $E$, Arlt $E$, Hohensinn M, Moussa $S$, Jell $G$, Alió JL, et al Vecto analysis of astigmatism correction after toric intraocular lens implantation. J Cataract Refract Surg. 2015;41:790-99. 